\title{
CADEIA PRODUTIVA DE BIOMASSA DE ORIGEM FLORESTAL NO PLANALTO SUL DE SANTA CATARINA
}

\author{
Flávio José Simioni ${ }^{1}$, Vitor Afonso Hoeflich ${ }^{2}$ \\ ${ }^{1}$ Eng. Agrônomo, Dr., UNIPLAC, Lages, SC, Brasil - simioni@uniplac.net \\ ${ }^{2}$ Eng. Agrônomo, Dr., Depto. de Economia Rural e Extensão, UFPR, Curitiba, PR, Brasil - hoeflich@ufpr.br
}

Recebido para publicação: 30/01/2008 - Aceito para publicação: 23/10/2008

\begin{abstract}
Resumo
O objetivo do artigo foi caracterizar e delimitar os segmentos que compõem a cadeia produtiva de energia a partir de biomassa de origem florestal no planalto sul de Santa Catarina, visando fornecer informações que subsidiem os gestores públicos e privados na tomada de decisões estratégicas para o melhor desempenho competitivo dessa cadeia. Utilizou-se como metodologia o modelo de análise de cadeia produtiva proposto por Castro et al. (1998) e Castro (2002). As principais conclusões foram: a) verificou-se que o segmento da produção florestal está centrado na produção de madeiras do gênero Pinus, com alta integração vertical e elevado nível tecnológico, e suas maiores preocupações são com a pequena produção não integrada à indústria, com as restrições em função da legislação ambiental e com a evolução da área plantada; b) o segmento da indústria, com exceção da celulose e papel, apresenta deficiências no que se refere à tecnologia, à gestão de processos e à qualificação dos recursos humanos, e não possui ações de planejamento coletivo visando uma reestruturação para a melhoria de suas condições de competitividade; c) para o segmento de geração de energia de biomassa, verificou-se uma tendência de aumento dos investimentos, visando o aproveitamento dos resíduos florestais e das indústrias de base florestal para a geração de energia térmica e elétrica, sendo que um dos fatores determinantes é a identificação da disponibilidade e do potencial de geração de resíduos na região; d) o tratamento não adequado dispensado aos resíduos florestais e industriais é uma das dificuldades atuais que limitam seu aproveitamento como matéria-prima para a geração de energia.

Palavras-chave: Cadeia produtiva de energia; biomassa de origem florestal; energia de biomassa.
\end{abstract}

\begin{abstract}
Biomass Productive chain from forest origin in the southern plateau of Santa Catarina. The objective of this paper is to characterize and to delimit the segments that compose the energy productive chain from forest origin biomass in the Southern Plateau of Santa Catarina, aiming to provide information for private and public managers how to take strategic decisions as a way to get their best performance. The analysis of productive chain proposed by Castro et al. (1998) was the methodology used. The main conclusions were: a) the forest production segment is centered in the production of wood from pinus species, with high vertical integration, high technological level having as main concerns: the small production is not industry integrated, environmental legislation restrictions and evolution of planted areas; b) the segment of industry, except pulp and paper, has limitations in obtaining new technologies, management of processes and human resources qualification, not implementing collective planning actions aiming at a restructuring processes to improve their competitiveness; $c$ ) in the sector of biomass energy generation, there is a trend in the increase of investments that use forest residues and forest industries for the generation of thermal and electric energy, in which the most determinant factors are the identification of availability and potential of generation of residues in the region; d) the forest and industrial residues are not being used properly and this is one of the current difficulties that limit their use as raw materials for energy generation.

Keywords: Energy productive chain; biomass of forest origin; biomass energy.
\end{abstract}

\section{INTRODUÇÃO}

Nos últimos anos, a questão energética tem despertado interesse, sobretudo na busca de fontes de energia alternativas, com menor impacto ambiental do que os combustíveis fósseis. A partir dessa 
preocupação, a madeira tem se constituído em uma alternativa para a geração de energia, inclusive com a criação de políticas setoriais de incentivo ao desenvolvimento de tecnologias mais eficientes para a conversão da biomassa em energia térmica e elétrica.

Essa nova configuração, na qual a biomassa de origem florestal ou madeireira passou a ser mais disputada, desencadeou maior concorrência entre os diferentes segmentos da cadeia na busca dessa matéria-prima. Nesse caso, a produção de energia concorre diretamente com a produção de celulose e papel, além de alguns tipos de chapas, pois esses segmentos industriais utilizam a mesma biomassa como principal matéria-prima. Assim, os resíduos de biomassa de origem florestal deixaram de ser vistos como "lixo" e passaram a ser tratados como matéria-prima para a geração de energia.

Esse movimento necessita ser estudado, visando orientar a tomada de decisões e a proposição de políticas públicas e privadas para o planejamento estratégico regional do setor, no intuito de buscar o seu crescimento e desenvolvimento sustentável. Assim, o objetivo do artigo foi caracterizar e delimitar os segmentos que compõem a cadeia produtiva de energia a partir de biomassa de origem florestal no Planalto Sul de Santa Catarina, visando fornecer informações que subsidiem os gestores públicos e privados na tomada de decisões estratégicas para o melhor desempenho competitivo dessa cadeia.

\section{METODOLOGIA}

Para a caracterização e delimitação da cadeia produtiva de energia a partir de biomassa florestal, utilizou-se o modelo de análise proposto por Castro et al. (1998) e Castro (2002), utilizado pela EMBRAPA na prospecção de demandas tecnológicas de cadeias produtivas.

O desenho da cadeia produtiva consiste na delimitação da cadeia, identificando os segmentos que a compõem, bem como o fluxo físico dos materiais desde a origem (segmento insumos) até o consumidor final. Cada segmento foi caracterizado com informações sobre o processo produtivo, seus limites, produtos e outras informações que, de modo mais específico, foram importantes para se entender a dinâmica da cadeia produtiva como um todo.

A pesquisa teve como área de abrangência o planalto sul do estado de Santa Catarina, considerando a área geográfica compreendida por uma distância de, aproximadamente, $120 \mathrm{~km}$ do município de Lages. A região do estudo foi escolhida por caracterizar-se como um importante polo de produção de madeira, sobretudo de espécies do gênero Pinus, e por conter uma das maiores concentrações de maciços florestais do Estado. Várias empresas fazem parte desse complexo produtivo (ou cluster), tais como a de celulose e papel (que representa um importante centro de produção de embalagens) e a de madeira sólida e móveis, totalizando cerca de 450 empresas (HOFF; SIMIONI, 2004).

As informações foram coletadas via dados secundários, entrevistas com aplicação de questionário e grupo focal (Focus Group).

\section{RESULTADOS E DISCUSSÃO}

A figura 1 apresenta a cadeia produtiva de energia e o mercado de biomassa de origem florestal destinada à produção de energia, respectivamente, e contempla as instituições que fazem parte, os produtos envolvidos e as transações ( $\mathrm{T}$ ) efetuadas entre os agentes. O estreito vínculo com as outras cadeias se deve ao fato de a produção de energia utilizar os "resíduos" das indústrias como matéria-prima. Assim, a madeira proveniente das florestas é transformada, por processos mecânicos ou químicos, em uma gama variada de produtos, gerando resíduos (biomassa) utilizados na produção de energia.

Com base nos esquemas representativos da cadeia produtiva de energia, sua caracterização pode ser feita considerando-se os seguintes segmentos: insumos, produção florestal, indústria de transformação da madeira e usina de geração de energia, sendo que a caracterização desses segmentos é apresentada na sequência.

\section{Segmento insumos}

Os insumos específicos à produção florestal são as mudas florestais, equipamentos de plantio e colheita florestal, além de determinados produtos fitossanitários. Outros insumos, como fertilizantes, corretivos e combustíveis também são utilizados na produção florestal, entretanto não são específicos. 


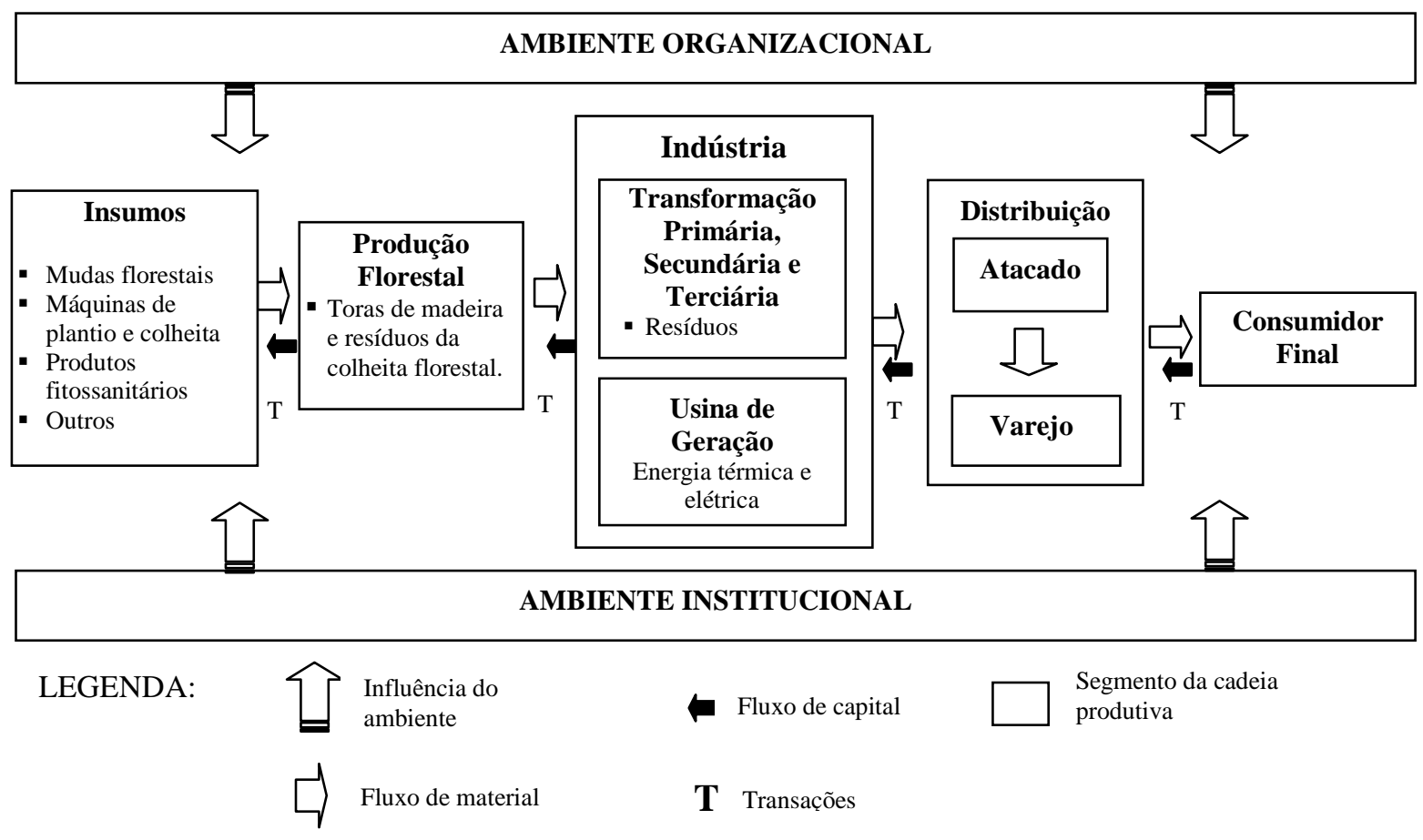

Fonte: Elaborado pelos autores com base no modelo de Castro et al. (1998) e Castro (2002).

Figura 1. Cadeia produtiva de energia de biomassa de origem florestal no Planalto Sul de Santa Catarina.

Figure 1. Productive chain of biomass energy from forestry origin in the southern plateau of Santa Catarina.

A produção de mudas de espécies florestais é realizada em viveiros especializados, sendo que existem na região duas tipologias diferenciadas: a) viveiros especializados, que atuam como terceirizados de grandes empresas e têm como objetivo principal produzir mudas para atender o plantio de novas áreas com florestas das próprias empresas ou para o fomento florestal; b) produtores de mudas não registrados, que produzem mudas para atender as oscilações de demanda, no entanto, sem acompanhamento dos órgãos de físcalização e apresentando produto sem comprovação de qualidade e procedência.

O maior problema relacionado a esse insumo refere-se à má qualidade das mudas produzidas por viveiristas do segundo grupo. Os reflexos desta prática são: menor incremento em volume e menor uniformidade das plantas. Quanto a esse aspecto, o Ministério da Agricultura, EPAGRI e FATMA estão desenvolvendo ações no sentido de orientar e fiscalizar o funcionamento dos viveiros, cobrando a apresentação de responsável técnico e licenciamento ambiental.

Na região do Planalto Sul de Santa Catarina há cerca de 40 (quarenta) viveiros, com capacidade de produzir 25-35 milhões de mudas por ano. A grande parte das mudas produzidas é do gênero Pinus, em função da maior concentração de cultivo dessa espécie na região de estudo.

Os equipamentos de plantio de mudas e de colheita florestal são estratégicos à atividade de silvicultura e significativamente importantes para a cadeia produtiva, pois conferem maior nível de automação aos processos e, consequentemente, maior produtividade (rendimento operacional) tanto no plantio quanto na colheita.

Existem, ainda, produtos fitossanitários específicos para o controle de pragas em plantios florestais. No que tange ao controle da vespa-da-madeira, as empresas privadas e a EMBRAPA Florestas atuam em parceria na prevenção e controle. A forma encontrada foi a criação de um Fundo Nacional de Controle da Vespa-da-Madeira (FUNCEMA), que viabiliza a realização de pesquisas e a produção em laboratório de agentes controladores utilizados pelos produtores florestais.

\section{Segmento da produção florestal}

Os primeiros plantios florestais de espécies do gênero Pinus foram realizados na década de 60, na ocasião da implantação das primeiras fábricas de celulose e papel nos municípios de Correia Pinto e Otacílio Costa. Em função de sua boa adaptabilidade e produtividade, o cultivo de florestas com essa 
espécie cresceu significativamente, impulsionado pelos incentivos fiscais para projetos de reflorestamento. Com o passar do tempo, a madeira do gênero Pinus também passou a ser a principal matéria-prima das indústrias madeireiras da região, dada a escassez das florestas naturais de araucária. Desse modo, a atividade florestal baseada na cultura do Pinus tornou-se uma importante alternativa econômica para a região.

A atividade de cultivo de florestas pode ser verificada em três tipos básicos:

1. Produção florestal integrada: ocorre quando a atividade de produção florestal integra ou faz parte da estrutura da empresa (integração vertical). É realizada pelas empresas de celulose e papel e de transformação mecânica, as quais detêm a maior área de cultivo de florestas na região.

2. Empresas florestais: ocorre quando a empresa é especializada na produção florestal, não realizando atividades de processamento da madeira.

3. Produtores rurais florestais: são, na sua maioria, pequenos produtores rurais que cultivam florestas em suas propriedades, em um sistema de produção diversificado.

O Levantamento Agropecuário Catarinense - LAC (SANTA CATARINA, 2006) apontou que a região de Lages possui 2.613 produtores com 85.688 ha de plantios florestais, representando cerca de $20 \%$ da área total do Estado. A análise dos dados evidencia que as florestas estão concentradas em grandes propriedades rurais:

a) cerca de 53 mil ha, $62 \%$ do total da área cultivada, estão concentrados em apenas 187 produtores, com área de plantios florestais maior ou igual a 100 ha, os quais representam $7,2 \%$ do número total de produtores;

b) por outro lado, 1080 produtores com menos de 5 ha, que representam $41,3 \%$ do total de produtores, detêm apenas 2.359 ha, ou seja, $2,8 \%$ da área plantada na região;

c) no Estado, a situação é semelhante, ou seja: $1,1 \%$ dos maiores produtores detêm $42,7 \%$ da área cultivada, enquanto $63,4 \%$ dos menores produtores possuem apenas $10,43 \%$ da área.

Os plantios florestais são realizados, basicamente, de duas formas:

- Plantios em alta densidade, visando o fornecimento de matéria-prima para a produção de celulose e papel, com o corte raso aos 14 anos de idade.

- Plantios com menor densidade, visando o uso múltiplo da floresta. Nesse sistema, são realizados dois desbastes (no $9^{\circ}$ e no $14^{\circ}$ ano) e corte final entre o $20^{\circ}$ e $25^{\circ}$ ano, que dá a condição de se produzirem toras de maior diâmetro, que podem ser utilizadas para laminação ou serrarias.

Os produtos oriundos das florestas podem ser agrupados em:

- Toras de madeira: normalmente separadas por classes diamétricas, podendo ser finas, médias e grossas.

- Resíduos da colheita florestal: fazem parte as pontas das árvores, galhos, folhas e outras partes que ficam na floresta após a colheita das toras de madeira.

De acordo com Simioni; Andrade (2006), cerca de 96\% da madeira consumida pelas empresas da região de Lages são de espécies de Pinus e 3\% de espécies de Eucalyptus, o que representa o perfil da produção da região. Cerca de $66 \%$ do volume de toras de madeira de Pinus possuem diâmetro menor que $20 \mathrm{~cm}$, relacionado ao alto consumo para a produção de celulose e papel. Para o caso do Eucalyptus, não se verificou a prática da classificação de acordo com o diâmetro, sendo $97 \%$ destinados à produção de celulose, possuindo diâmetro menor que $20 \mathrm{~cm}$. seguintes usos:

Os produtos da floresta são destinados, conforme identificado pela pesquisa de campo, para os

- Indústria de celulose e papel: utiliza toras de madeira de baixo diâmetro, na sua maioria menores que $20 \mathrm{~cm}$. Representa cerca de $40 \%$ do consumo de madeira da região de estudo.

- Indústria de transformação mecânica: utiliza toras de madeira de diâmetro médio a alto, preferencialmente maior que $20 \mathrm{~cm}$. A qualidade interna da madeira, definida pela ausência de nós e regularidade do espaçamento dos anéis de crescimento, bem como a qualidade externa, definida pela ausência de conicidade e tortuosidade, são características desejadas.

- Produção de energia: utilizam-se resíduos da colheita florestal (pontas das árvores e galhos) e toras finas, especialmente as de madeiras consideradas juvenis.

Os resíduos da colheita florestal ainda são pouco utilizados para a produção de energia, devido à dificuldade de adaptação do processo de colheita para viabilizar o seu aproveitamento. Um primeiro aspecto a observar é a obtenção dos resíduos livres de materiais contaminantes, tais como a presença de 
pedras e terra que ficam aderidos. Segundo, a viabilidade econômica do aproveitamento desses resíduos, uma vez que o sistema de colheita torna-se mais lento, diminuindo a produtividade.

Os preços da madeira em tora recebidos pelos produtores em Santa Catarina (Figura 2) podem ser divididos em três períodos distintos. No primeiro período, entre janeiro de 1996 e dezembro de 2000, verifica-se que houve uma gradativa redução dos preços, principalmente com a madeira de eucalipto, passando de $\mathrm{R} \$ 115,00 / \mathrm{m}^{3}$ para cerca de $\mathrm{R} \$ 70,00 / \mathrm{m}^{3}$, uma redução de $40 \%$. Para o pinus, a redução foi de $16 \%$, passando de $\mathrm{R} \$ 77,00 / \mathrm{m}^{3}$ para $\mathrm{R} \$ 65,00 / \mathrm{m}^{3}$. No segundo período, o preço da madeira, tanto de pinus quanto de eucalipto, sofreu significativa elevação, chegando a $R \$ 140,00 / \mathrm{m}^{3}$ para o eucalipto e $\mathrm{R} \$ 150,00 / \mathrm{m}^{3}$ para o pinus no início de 2006 , ou seja, uma elevação de $100 \%$ e $130 \%$, respectivamente. O terceiro período - de 2006 até início de 2008 -, é marcado por uma estabilização dos preços da madeira. Vários são os fatores que podem explicar essa variação, dentre os quais se destacam a relação entre oferta e demanda de toras, a dinâmica do mercado interno e externo, os investimentos regionais e a demanda por biomassa.

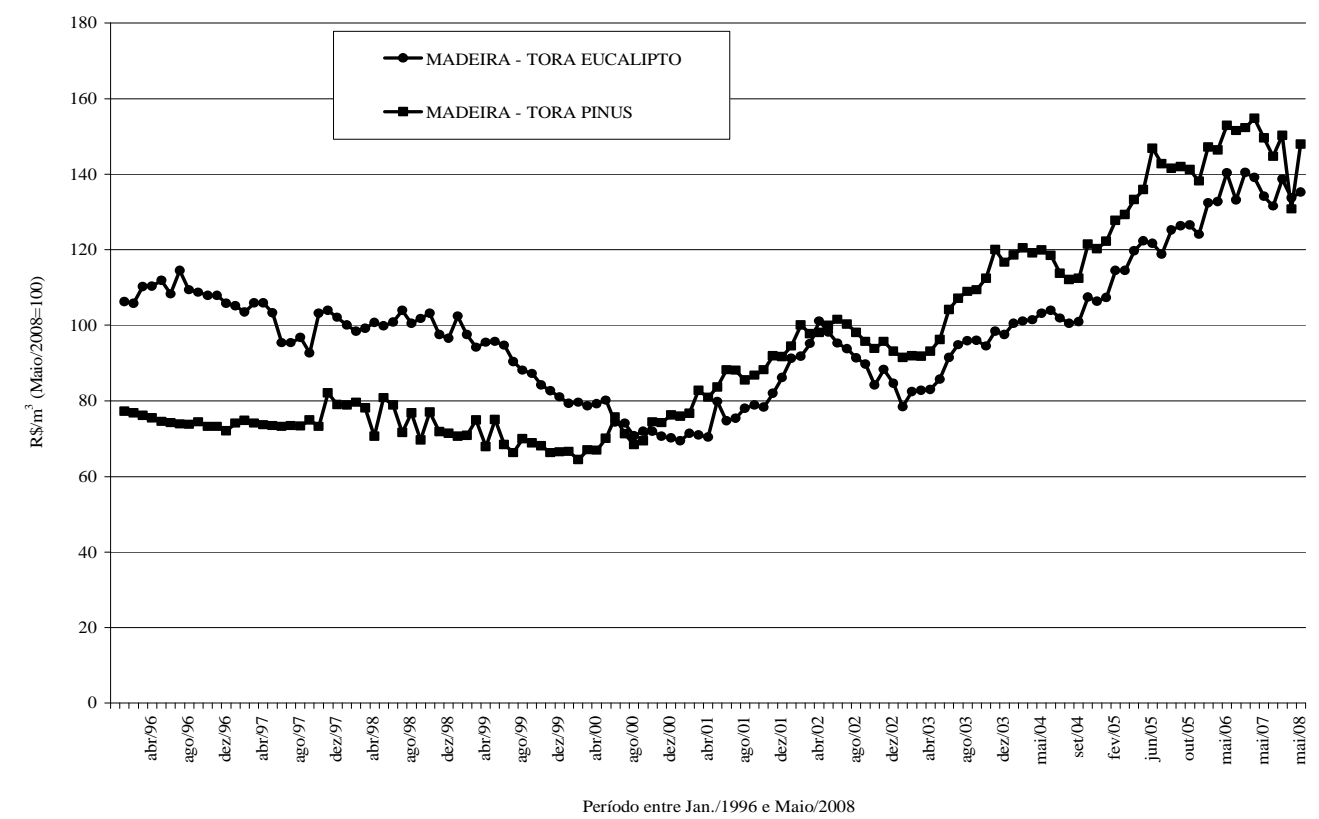

Figura 2. Preços de toras de madeira de eucalipto e pinus $\left(\mathrm{R} \$ / \mathrm{m}^{3}\right)$ pagos ao produtor em Santa Catarina, no período entre janeiro de 1996 e maio de 2008.

Figure 2. Prices of eucalyptus and pine $\operatorname{logs}\left(\mathrm{R} \$ / \mathrm{m}^{3}\right)$ paid to the producer in Santa Catarina, in the period between January 1996 and May 2008.

\section{Segmento da indústria}

Indústria de transformação mecânica

A indústria de transformação pode ser classificada em três níveis, conforme o grau ou intensidade de transformação da madeira:

a) Indústrias de transformação primária: fazem parte as serrarias e laminadoras que realizam as operações de desdobro. Os resíduos industriais desse processo são as cascas das toras (quando estas sofrem o descascamento), as costaneiras e a serragem. Geralmente são produzidos cavacos a partir de costaneiras sem casca, destinados às indústrias de celulose e papel. Os demais resíduos são destinados à produção de energia ou de painéis. As serrarias presentes na região de estudo destacam-se no âmbito estadual, representando $11,5 \%$ do total.

b) Indústrias de transformação secundária: fazem parte as indústrias de transformação mecânica que realizam operações de beneficiamento, produzindo uma gama variada de produtos de madeira sólida (forros, pisos, madeira para construção civil, etc.), painéis, chapas e artefatos, dentre outros, além das indústrias de celulose e papel. São geradas serragens, maravalha, destopos, refilos e pó. 
c) Indústrias de transformação terciária: incluem as indústrias que produzem produtos finais, como as moveleiras e convertedoras de papel. Os resíduos gerados nessa etapa são semelhantes aos da anterior, porém, com maior proporção de pó.

Quanto à produção na região de estudo, exceto móveis, verificou-se na pesquisa de campo que há uma concentração em relação a três produtos: painéis $(30,4 \%)$, madeira serrada $(25,1 \%)$ e lâminas $(20,7 \%)$. Destaca-se, entretanto, a produção de portas e de papel (kraftliner para caixas, sackskraft para sacos e papel tissue). De acordo com Hoff; Simioni (2004), a madeira serrada representava, em 2002, $52 \%$ do total produzido na região, seguida dos painéis, com $18 \%$. Nesse sentido, nota-se uma evolução do perfil da indústria, demonstrando que houve movimentos de transformação da matéria-prima para produtos de maior valor agregado.

Classificando as empresas pelo porte, a pesquisa de campo identificou um perfil composto pela predominância de pequenas e médias empresas, com $60,9 \%$ e $25,0 \%$, respectivamente. As grandes empresas representam $9,4 \%$ e são, basicamente, as empresas de celulose e papel, de portas e algumas madeireiras. Já as microempresas somam $4,7 \%$ e se caracterizam por pequenas serrarias e fábrica de artefatos. Destaca-se que as empresas de móveis sob medida não foram alvo da pesquisa de campo, o que alteraria significativamente os resultados, uma vez que se encontram em grande número e, quase que na sua totalidade, são microempresas.

Verificou-se a existência de um elevado grau de concentração da indústria: 30,8\% das empresas processam apenas $1,6 \%$ do volume total de madeira. Por outro lado, uma única empresa representa $43,1 \%$ do consumo de madeira. De outra forma, as 5 maiores empresas processam 56,3\% da madeira na região de estudo.

A madeira consumida pelas empresas provém, na sua maioria, de florestas próprias, representando mais de $73 \%$ da quantidade consumida. Isso reflete o alto grau de integração vertical da indústria, ou seja, as indústrias atuam no segmento da produção florestal como uma forma de garantia de suprimento de matériaprima. Do total de empresas entrevistadas (130), apenas 23, ou seja, $17 \%$ possuem suprimento via florestas próprias, o que caracteriza que os plantios florestais estão presentes nas maiores empresas.

A quantidade de resíduos destinada à produção de energia na região estudada está intrinsecamente relacionada ao segmento da indústria que gera produtos finais à base de madeira sólida. De acordo com pesquisa realizada por Simioni e Andrade (2006), o volume estimado de resíduos em toda a região é de cerca de 201 mil toneladas mensais. A tabela 1 apresenta a quantidade de resíduos classificados por tipo e sua participação percentual no total gerado, numa amostra de 70 (setenta) empresas.

Tabela 1. Quantidade (t/mês) e participação percentual dos resíduos industriais produzidos pela indústria de transformação mecânica da região de Lages/SC, 2006.

Table 1. Quantity ( $\mathrm{t} /$ month) and percentual rate of industrial residues produced by machinery transformation industry in the region of Lages/SC, 2006.

\begin{tabular}{lcr}
\hline Tipo de resíduo & Quantidade (t/mês) & \% \\
\hline Cavaco com casca & $37.738,0$ & 48,31 \\
Cavaco sem casca & $11.100,0$ & 14,21 \\
Serragem & $10.851,0$ & 13,89 \\
Resíduo não qualificado & $8.350,0$ & 10,69 \\
Casca & $3.630,0$ & 4,75 \\
Maravalha & $2.190,0$ & 2,80 \\
Rolo-resto & $2.176,0$ & 2,79 \\
Destopo & 827,0 & 1,06 \\
Costaneira com casca & 690,0 & 0,78 \\
Lâmina & 290,0 & 0,37 \\
Refilo & 280,0 & 0,36 \\
Costaneira sem casca & 80,0 & 0,10 \\
Total & $78.122,0$ & 100,00 \\
\hline
\end{tabular}

Fonte: Simioni e Andrade (2006, p. 12).

Nota: A quantidade de resíduos refere-se a uma amostra de 70 (setenta) empresas que responderam adequadamente o questionário, representando cerca de $22 \%$ do total de empresas existentes na região.

Comparando o perfil da produção de resíduos verificada em 2004, por Brand; Neves (2005), e os dados obtidos na pesquisa de campo em 2006, nota-se a significativa evolução da produção de cavacos, 
que passou de $28,5 \%$ para $62,5 \%$. Essa evolução é explicada, em parte, pelo novo tratamento dado ao resíduo da indústria, que deixou de ser considerado "lixo" e foi transformado em matéria-prima para a produção de energia. Essa prática é resultado da valorização comercial dos resíduos, em função do aumento da procura para a geração de energia, e do fornecimento de picadores por parte da usina de cogeração, na forma de comodato, para seus fornecedores. Essa tendência foi confirmada pelas informações obtidas junto às empresas vendedoras de máquinas para o setor madeireiro, constatando-se o significativo aumento das vendas de picadores de madeira.

Quanto às características técnicas dos resíduos produzidos na região, algumas são desejadas pelas empresas que a adquirem para uso na produção de energia, quais sejam: separação por categoria de resíduo, ausência de impurezas (como pedra, terra e outros materiais) e teor de umidade relacionado ao poder calorífico (energia liberada pela queima).

A separação dos resíduos por categoria faz-se necessária em função do tipo de grelha da caldeira utilizada no processo de queima para a geração de energia, ou seja, requer um combustível homogêneo quanto à sua granulometria. Assim, as empresas adquirem vários tipos de material com granulometria variada e necessitam realizar uma mistura, chamada de blendagem, para preparar o combustível com granulometria adequada para o processo de queima.

Nesse aspecto, dada a importância da granulometria dos resíduos, a empresa de cogeração tem adquirido picadores de madeira e cedido aos seus fornecedores para que os resíduos maiores sejam picados e transformados em cavacos. O tipo de resíduo está intimamente relacionado com o poder calorífico, ou seja, a quantidade de energia gerada, e, por essa razão, é determinante no preço final do produto.

A qualidade dos resíduos representada pela ausência de impurezas também é uma característica importante, uma vez que a presença de material não combustível aumenta o teor de cinzas. Como as cinzas são consideradas lixo industrial, requerem tratamento adequado de acordo com a legislação ambiental.

A característica mais importante é o poder calorífico do resíduo, que está intimamente relacionado ao teor de umidade. Quanto mais seco for o resíduo, maior será seu poder calorífico. Assim, o teor de umidade passou a determinar o preço do resíduo adquirido pela usina de cogeração. No início de sua operação, a usina adquiria resíduos sem muitos critérios de classificação quanto ao tipo e ao teor de umidade, mas, com o tempo, passou a praticar preços diferenciados de acordo com essas características. Esse comportamento tem provocado uma mudança significativa nos seus fornecedores: $1^{\circ}$ ) os resíduos industriais passaram a ter melhores oportunidades de remuneração e deixaram de ser tratados como lixo para serem tratados como matéria-prima para a geração de energia; $2^{\circ}$ ) os fornecedores passaram a classificar os resíduos por categoria, incorporando as práticas de descascar as toras de madeira, separando a casca da madeira, realizar a picagem de costaneiras e outros materiais para a produção de cavacos e realizar o armazenamento dos resíduos. Essas práticas, de modo geral, sinalizam que há um movimento de profissionalização e adequação do tratamento dos resíduos para fins energéticos.

A quantidade de resíduos destinada à produção de energia representa cerca de 200 mil toneladas/mês e é proveniente de toda a indústria de processamento, sendo caracterizada como resíduo industrial. A produção é distribuída para os seguintes segmentos consumidores:

- Cogeração de energia: a empresa Tractebel Energia, localizada em Lages (SC) é a única empresa na região que atua na cogeração. Consiste em uma planta industrial de cogeração de energia elétrica e térmica, onde a queima dos resíduos é destinada à produção de vapor que é utilizado tanto para a secagem de madeiras como para a produção de energia elétrica. A empresa utiliza praticamente todo tipo de biomassa de origem florestal, com exceção de material de baixa granulometria, devido às características estruturais dos equipamentos de queima (caldeira).

- Energia térmica: a maior parte dos resíduos disponível na região é destinada à produção de energia térmica, sobretudo nas próprias empresas, para a utilização de vapor nos seus processos industriais. Parte é comercializada para empresas de cerâmica vermelha, de alimentos e vulcanizadoras, entre outras.

- Produção de celulose: as empresas de celulose presentes na região utilizam biomassa na forma de cavaco sem casca e toras de madeira de desbastes, tanto para a produção de celulose como de energia. 
- Cama de aves: os resíduos do tipo maravalha são comercializados para produtores de frango para serem utilizados como cama nos aviários.

De acordo com as características dos resíduos produzidos na região e a sua utilização para a produção de energia, tomando-se como exemplo a biomassa adquirida pela Tractebel Energia (BRUTTI; SIMIONI, 2006), cavaco, casca e serragem são os principais resíduos comercializados. Os demais tipos são utilizados para outros fins, ou, ainda, são transformados em cavacos para então serem vendidos com destino à produção de energia. Esse comportamento é explicado, em parte, pela melhor remuneração obtida na comercialização dos resíduos para outras finalidades que não a energia. Destaca-se a comercialização do rolo-resto do processo de laminação para a construção civil e a maravalha para uso em cama de criação de aves. Os preços dos resíduos são apresentados na tabela 2.

Os dados da tabela 2 evidenciam que houve um aumento do preço real dos resíduos desde 2001 até 2006, com exceção da maravalha, que aumentou o preço em 2005 e caiu em 2006. O aumento do preço dos resíduos na região pode ser explicado por:

1. aumento do preço da madeira verificado nos últimos anos, conforme Gráfico 1;

2. aumento da demanda dos resíduos para a produção de energia, em função da instalação de uma usina de cogeração de energia a partir de biomassa na região e substituição do óleo combustível (derivado de petróleo) por caldeiras que utilizam biomassa na geração de vapor em várias empresas da região.

Essa tabela, associada à tendência de aumento do consumo de biomassa para a geração de energia, configura um cenário de aumento do preço dos resíduos florestais e industriais. Como desdobramento, novas relações de poder são esperadas com as alterações nos padrões de concorrência, tais como o uso múltiplo da floresta e o estabelecimento de contratos de fornecimento.

Tabela 2 Preços praticados na comercialização dos resíduos na região de Lages/SC.

Table 2. Prices practiced in the commercialization of the residues in the region of Lages/SC.

\begin{tabular}{|c|c|c|c|c|}
\hline \multirow{2}{*}{ Tipo de resíduo } & \multicolumn{3}{|c|}{ Preços médios de venda $(\mathrm{R} \$ / \mathrm{t})$} & \multirow{2}{*}{$\begin{array}{c}\text { Variação } \\
\text { percentual } \\
(\mathbf{2 0 0 6 / 2 0 0 1 )})\end{array}$} \\
\hline & 2001 & 2005 & 2006 & \\
\hline Maravalha & 31,55 & 63,68 & 93,76 & 197,17 \\
\hline Cavaco sem casca & 30,93 & 62,11 & 61,50 & 98,82 \\
\hline Cavaco com casca & 25,76 & 36,64 & 42,84 & 66,34 \\
\hline Serragem & 5,39 & 17,15 & 24,63 & 357,06 \\
\hline Refilos & 17,00 & 18,50 & 40,00 & 135,34 \\
\hline Costaneiras & 16,67 & 16,03 & 30,00 & 79,95 \\
\hline Destopos & 13,02 & - & 24,00 & 84,27 \\
\hline Cascas & - & 17,74 & 44,50 & 250,82 \\
\hline
\end{tabular}

Fonte: Preços do ano 2001 (Brand et al., 2001, p. 7), do ano 2005 (Brand e Neves, 2005, p. 12) e do ano 2006 (dados da pesquisa de campo realizada pelos autores).

Notas: Os preços foram atualizados pelo IGP-M considerando os índices médios de cada ano e julho/2006=100.; Os campos identificados por (-): dados não disponíveis.

\section{Usina de geração de energia}

A biomassa utilizada para a produção de energia é proveniente, basicamente, dos resíduos industriais gerados nos processos de utilização da madeira, sobretudo da indústria de transformação mecânica e, em menor escala, de resíduos da colheita florestal e de toras finas oriundas dos desbastes das florestas. De uso mais recente, esses resíduos florestais (ponta de árvores e galhos) também são utilizados para a geração de energia, como forma de maximizar o aproveitamento da floresta, processo que se denomina de uso múltiplo.

A utilização dos resíduos para a geração de energia pode ser de duas maneiras:

1. Produção de energia térmica: consiste no aproveitamento do calor obtido pela queima dos resíduos para a geração de vapor, objetivando a secagem de madeira, lâmina, celulose, papel ou para a produção de produtos de outras cadeias produtivas, como ocorre na cerâmica vermelha e nas agroindústrias de alimentos e bebidas presentes na região.

2. Cogeração de energia: consiste na geração de energia térmica e elétrica através de um circuito fechado de geração de vapor. $\mathrm{O}$ vapor resultante da queima da biomassa passa por 
turbinas e geradores, produzindo energia elétrica, que é incorporada na rede de distribuição de energia elétrica (CELESC Distribuição S.A.). Parte do vapor produzido na usina é utilizada por indústrias que estão próximas à unidade de cogeração.

A caracterização do sistema de produção de energia térmica (vapor) foi qualitativamente sistematizada pela pesquisa de campo, uma vez que as empresas não realizam acompanhamento estatístico da quantidade de biomassa consumida e de vapor gerado. $\mathrm{Na}$ indústria de madeira sólida, o sistema é composto, na grande maioria dos casos, por uma caldeira que produz energia térmica (vapor), utilizado na secagem de madeiras. Na indústria de celulose e papel, o vapor participa em diferentes fases do processo, desde o cozimento dos cavacos até a secagem do papel, assim como ocorre em outras indústrias, como na da cerâmica vermelha, na alimentícia e na de bebidas.

A grande quantidade de resíduos disponível na região fez com que, no final da década de 90, fosse apontada como uma das ações do Plano de Desenvolvimento Tecnológico Regional (PDTR) a instalação de uma usina de cogeração de energia em Lages. Assim, em 2002 iniciaram-se as instalações da Unidade de Cogeração Lages (UCLA), do grupo Tractebel Energia S.A., como forma de buscar o aproveitamento mais racional dos resíduos da indústria. A usina atua com capacidade instalada de $28 \mathrm{MW}$ de energia elétrica, além da produção de $25 \mathrm{t} / \mathrm{h}$ de vapor para empresas madeireiras localizadas no seu entorno.

\section{CONCLUSÕES}

O trabalho identificou os segmentos e fluxos que fazem parte da cadeia de energia de biomassa de origem florestal, estabelecendo as inter-relações com outras cadeias produtivas presentes na região, tais como a de painéis, a de madeira sólida, a de móveis e a de papel. Verificou-se o aproveitamento de resíduos das plantações florestais e da indústria de transformação da madeira como característica desse processo.

O segmento da produção florestal está centrado na produção de madeiras do gênero Pinus, com alta integração vertical e elevado nível tecnológico. Sua maior preocupação deve-se à pequena produção não integrada à indústria, às restrições em função da legislação ambiental e à evolução da área plantada. O segmento da indústria, com exceção da celulose e papel, apresenta deficiências no que se refere à tecnologia, gestão de processos e qualificação dos recursos humanos, não possuindo ações de planejamento coletivo visando uma reestruturação para a melhoria de suas condições de competitividade.

No que se refere à geração de energia de biomassa, observou-se uma tendência de aumento dos investimentos visando o aproveitamento dos resíduos florestais e das indústrias de base florestal para a geração de energia térmica e elétrica, sendo que um dos fatores determinantes é a identificação da disponibilidade e do potencial de geração de resíduos na região. O tratamento inadequado dispensado aos resíduos florestais e industriais é uma das dificuldades que limitam seu aproveitamento como matériaprima para a geração de energia.

\section{REFERÊNCIAS}

BRAND, M. A.; NEVES, M. D. Levantamento da disponibilidade dos resíduos industriais e florestais de madeira e avaliação da variação de sua qualidade energética em função das condições climáticas anuais, na região de Lages - Santa Catarina. Lages: UNIPLAC: Tractebel Energia, 2005. 73 p. Relatório de Pesquisa.

BRAND, M. A.; SIMIONI, F. J.; ROTTA, D. N. H.; ARRUDA, L. G. P. Caracterização da produção e uso dos resíduos madeiráveis gerados na indústria de base florestal da região serrana catarinense. Lages: UNIPLAC, 2001.23 p. Relatório de Pesquisa.

BRUTTI, R. C.; SIMIONI, F. J. Caracterização e controle do abastecimento de biomassa de uma usina de co-geração de energia. In: CONGRESSO BRASILEIRO DE INDUSTRIALIZAÇÃO DA MADEIRA E PRODUTOS DE BASE FLORESTAL, 2., 2006, Curitiba. Anais... Curitiba: IPEF, 2006. p. 1-10. 
CASTRO, A. M. G. de. Cadeia produtiva e prospecção tecnológica como ferramenta para a gestão da competitividade. In: SIMPÓSIO DE GESTÃO DE TECNOLOGIA, 22., 2002, Salvador. Anais... São Paulo: FEA/USP, 2002.

CASTRO, A. M. G. de; LIMA, S. M. V.; GOEDERT, W. J.; FREITAS FILHO, A.; VASCONCELOS, J. R. P. Prospecção tecnológica de cadeias produtivas e sistemas naturais. Brasília, DF: Embrapa, 1998. $568 \mathrm{p}$.

HOFF, D. N.; SIMIONI, F. J. O setor de base florestal na serra catarinense. Lages: Editora Uniplac, 2004. 268 p.

SANTA CATARINA. Secretaria de Estado da Agricultura e Desenvolvimento Rural. Levantamento Agropecuário de Santa Catarina, 2002-2003. Florianópolis: Epagri. Disponível em: <http:www.epagri.rctsc.br> Acesso em: 28/09/2006.

SIMIONI, F. J.; ANDRADE, S. Identificação e prospecção de demanda de madeira e biomassa na região do planalto sul de Santa Catarina. Lages: Uniplac, 2006. 22 p. Relatório de Pesquisa. 